\title{
Fire severity estimation from space: A comparison of active and passive sensors and their synergy for different forest types
}

ARTICLE in INTERNATIONAL JOURNAL OF WILDLAND FIRE · JUNE 2015

Impact Factor: 2.51

3 AUTHORS, INCLUDING:

Mihai A. Tanase

University of Melbourne

40 PUBLICATIONS 178 CITATIONS

SEE PROFILE
Cristina Aponte

University of Melbourne

28 PUBLICATIONS 139 CITATIONS

SEE PROFILE 
This paper has been accepted for future publication in International J ournal of Wildland Fire. Please refer this work as: "M. Tanase, R. Kennedy, and C. Aponte, Fire severity estimation from space: A comparison of active and passive sensors and their synergy for different forest types, in press, International J ournal of Wildland Fire". Alternatively, lookup for the updated reference on the publisher website. Minor changes may occur in the published version. Formatting is not final.

\title{
Fire severity estimation from space: A comparison of active and passive sensors and their synergy for different forest types
}

\author{
M. A. Tanase A, R. Kennedy ${ }^{B}$ and C. Aponte ${ }^{A}$ \\ A School of Ecosystem and Forest Sciences, The University of Melbourne, 500 Yarra Boulevard, \\ Richmond, Vic. 3121, Australia

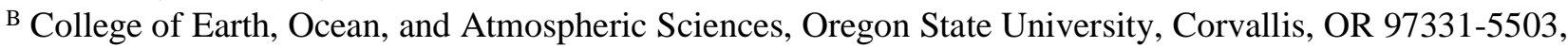 \\ U.S.
}

\begin{abstract}
Monitoring fire effects at landscape level is viable from remote sensing platforms providing repeatable and consistent measurements. Previous studies have estimated fire severity using optical and synthetic aperture radar (SAR) sensors, but to our knowledge, none have compared their effectiveness. Our study carried out such a comparison by using change detection indices computed from pre- and post-fire L-band space borne SAR datasets to estimate fire severity for seven fires located on three continents. Such indices were related to field estimated fire severity through empirical models, and their estimation accuracy was compared. Empirical models based on the joint use of optical and radar indices were also evaluated. The results showed that, optical based indices provided more accurate fire severity estimates. On average, overall accuracy increased from 61\% (SAR) to 76\% (optical) for high biomass forests. For low biomass forests (i.e., above ground biomass levels below the L-band saturation point), radar indices provided comparable results, with overall accuracy being only slightly lower when compared to optical indices (69\% vs. $73 \%$ ). The joint use of optical and radar indices decreased the estimation error and reduced misclassification of unburnt forest by $9 \%$ for eucalypt and $3 \%$ for coniferous forests.
\end{abstract}

Additional keywords: Landsat, ALOS PALSAR, L-band, radar, accuracy assessment, radar-optical synergy, CBI

\section{Introduction}

Fire is the most important disturbance agent on a global scale with about 350 million hectares of land being annually affected (Van Der Werf et al. 2006). However, not all areas within a fire perimeter are equally affected by fire, with impacts varying considerably. Depending on forest type, up to $35 \%$ of the area may remain largely intact (Kasischke and Hoy 2012; Kolden et al. 2012). The degree of environmental change caused by fires is often expressed through fire severity indices providing information on the loss of organic matter above and belowground (Keeley 2009). Previous studies used fire severity to predict ecosystem responses such as post-fire soil erosion and vegetation recovery, which in turn affect water cycles and biodiversity (Benyon and Lane 2013). Fire severity was also related to impacts in terms of loss of life, infrastructure damage and suppression costs (Keeley et al. 2008). Therefore, information on fire severity is a critical tool for evaluating post-fire effects and designing mitigation activities. The poor spatial representation and considerable effort when gathering ground fire severity estimates make remote sensing essential for landscape level assessments (Miller and Yool 2002; Landmann 2003; Boer et al. 2008). Remote sensing of fire severity has been accomplished using passive sensors such as the Landsat satellite series and active sensors such as Light Detection and Ranging (LiDAR) and Synthetic Aperture Radar - SAR (Miller and Thode 2007; French et al. 2008; Hoy et al. 2008; Wang and Glenn 2009; Tanase et al. 2010a; Tanase et al. 2011; Tanase et al. 2014; Montealegre et al. 2014 ). In addition, some studies used passive thermal sensors to relate fire radiative power to fire impacts (Heward et al. 2013).

Remote sensing data are commonly used in conjunction with field assessed fire severity which is routinely carried out using the composite burn index - CBI (Key and Benson 2006). CBI evaluates the magnitude of fire effects across vegetation strata from an ecological perspective. CBI uses a hierarchical sampling design by assessing different factors (e.g., litter, duff and dead fuel consumption, soil and rock cover/color, colonizing vegetation, percentage of green/black/brown foliage, tree mortality, etc.) and vegetation strata (substrate, shrubs, understory 
and various overstory layers). Average vegetation conditions are visually examined within a $15 \mathrm{~m}$ radius and the degree of change with respect to the presumed pre-fire status is recorded for each factor in values from zero (no change) to three (100\% change). Scored factors are averaged by strata. Strata values are subsequently used to produce severity scores for the understory (based on substrate, low shrubs and tall shrubs strata), overstory (based on one or more tree strata) and the entire plot (based on all strata). The result is a numerical value between 0 (unburnt) and 3 (high) representing the average fire impact (i.e., severity) at a specific site or for specific vegetation layers. CBI or its revised versions (e.g., GeoCBI - (de Santis and Chuvieco 2009)) are frequently used for calibrating and validating remotely sensed products (French et al. 2008).

A range of optical based remote sensing approaches (e.g., based on spectral reflectance, vegetation indices, supervised classification, decision trees, regression analysis, or spectral mixture analysis) are used to estimate fire effects over different biomes from boreal tundra and taigas to temperate forests, savannahs and rainforests (Lentile et al. 2006; French et al. 2008). The spatial resolution at which fire severity estimates are generated ranges from very high $(<5 \mathrm{~m})$ to relatively coarse $(>250 \mathrm{~m})$ depending on the sensor used (Viedma et al. 1997; Henry and Hope 1998; Riaño et al. 2002; Holden et al. 2010). Nevertheless, most studies take advantage of the moderate-resolution Landsat satellite series as evident in the reviews of Lentile et al. (2006) and French et al. (2008). Such studies have used single date or bi-temporal (i.e., change detection) approaches with the latter dominating in forested landscapes (Van Wagtendonk et al. 2004; Cocke et al. 2005; Epting et al. 2005; Wimberly and Reilly 2007; Allen and Sorbel 2008; Hall et al. 2008). Early research demonstrating the importance of near- and shortwave-infrared wavelengths (NIR and respectively SWIR) to estimate post-fire vegetation variability (López-García and Caselles 1991) underpinned fire severity estimation from optical sensors and allowed for the development of the normalized burn ratio (NBR) and its bi-temporal counterpart, the differenced NBR (dNBR), based on pre- and post-fire datasets (Key and Benson 2006). Empirical modeling of CBI as a function of dNBR has provided accurate fire severity estimates, with the reported determination coefficients usually being high $\left(\mathrm{R}^{2}>0.7\right)$ (Van Wagtendonk et al. 2004; Cocke et al. 2005; Epting et al. 2005; Wimberly and Reilly 2007; Allen and Sorbel 2008; Hall et al. 2008; Tanase et al. 2011). However, several studies have reported signal saturation at high CBI values ( $>2.5)$ in many ecosystems, with dNBR flattening out at medium to high severity levels (Van Wagtendonk et al. 2004; Key 2006; Wimberly and Reilly 2007; Hall et al. 2008; Tanase et al. 2011). Furthermore, some authors have reported weaker relationships between dNBR and CBI for boreal forests (Hoy et al. 2008; Murphy et al. 2008) or over non-forested sites such as woodlands, scrub and herbs or savannahs (Epting et al. 2005; Smith et al. 2005). Finally, reflectance based indexes often fail to produce accurate results for intermediate severity levels where multiple effects combine (Chuvieco et al. 2006; Tanase et al. 2011). Such limitations have been related to the NBR index itself since it might not optimally represent spectral displacements due to fire effects (Roy et al. 2006), its inability to discern between high severity sites due to variations in topography, solar elevation, or specific fuel conditions (Kasischke et al. 2008; Verbyla et al. 2008), saturation of spectral response at moderate to high severity levels (Verbyla et al. 2008; Tanase et al. 2011), or the higher NBR sensitivity to canopy severity coupled with differentiated effects along the forest vertical profile in many ecosystems (Allen and Sorbel 2008; Hoy et al. 2008). Additional limitations were related to the qualitative nature of fire severity estimates (Roy et al. 2006) and the linear averaging of strata scores when computing the CBI in boreal ecosystems where variations in CBI are mostly related to variations in the substrate layer (Kasischke et al. 2008).

Because of such limitations, additional studies focused on burned area mapping and, to some extent, fire effects estimation using alternative methods based on SAR data in boreal or tropical forests (Kasischke et al. 1992; Bourgeau-Chavez et al. 1994; Kasischke et al. 1994; Bourgeau-Chavez et al. 1997; Rignot et al. 1999; Siegert et al. 1999; Siegert and Hoffmann 2000; Siegert and Nakayama 2000; Bourgeau-Chavez et al. 2002; Menges et al. 2004). More recently, Tanase et al. (2010a; 2010b; 2010c) have related fire severity estimated through CBI field measurements or the dNBR to SAR data in semi-arid and boreal environments, with promising results being obtained from backscatter intensities and interferometric coherence. In addition, Tanase et al. (2014) demonstrated that fire severity could be estimated with virtually no need for field datasets using polarimetric target decomposition components. Such studies take advantage of information on vegetation structure contained in the SAR signal (Ferrazzoli et al. 1997), with radar backscatter from forests including direct scattering from crown elements, direct scattering from trunk, direct scattering from ground, crown-ground scattering, and trunk-ground scattering (double bounce). At higher wavelengths (i.e., $23 \mathrm{~cm}$ L-band) the radar signal penetrates forest canopy and interacts with large branches, tree stems, and the forest floor (Le Toan et al. 1992). Removal of leaves and branches by fire and the associated water loss (i.e., dryer vegetation) result in a decreased cross-polarized (VH and HV polarizations) backscatter at all wavelengths. However, Tanase et al. (2010a) demonstrated that L-band 
consistently outperformed X- and C-band when estimating fire effects. Although previous studies showed promising results, the use of polarimetric target decomposition components is far from operational due to the complex SAR processing and the lack of regular acquisitions of fully polarimetric SAR data at global levels. In addition, radar scattering is affected by a range of conditions such as rainfall and topography which negatively influence the estimation accuracy of fire severity (Tanase et al. 2010a; Tanase et al. 2010c). The destruction of vegetation canopy makes radar measurements sensitive to the state of the underlying ground (Saich et al. 1999), which results in scattering dependence not only on the forest parameters but also on the surface properties. This is particularly relevant for co-polarized waves ( $\mathrm{HH}$ and VV polarizations) with cross-polarized waves being less affected. Alternatively, change detection approaches, based on the ratio between pre- and post- fire radar datasets, would mathematically cancel out some of this effects (i.e., topography) - a major advantage compared to single date approaches where such effects had to be accounted for (Tanase et al. 2010a). Furthermore, a multi-temporal approach based on average pre- and respectively post-fire values has the potential to reduce radar speckle without the associated decrease in spatial resolution, thus improving fire severity estimation accuracy from SAR data.

Fire severity estimation is usually carried out using one sensor type (either optical, or SAR), with an assessment of their synergy being largely unexplored. Furthermore, to the knowledge of the authors, no study has compared the accuracy of fire severity estimation from such sensors. Therefore, the aim of this study was twofold: i) to compare fire severity estimation accuracy from optical and SAR sensors and ii) to evaluate the synergy between optical and SAR sensors for fire severity estimation. These objectives were tested at several locations characterized by different species composition and forest structures within a change detection approach. Since remote sensing sensors might better reflect fire impact on the top vegetation layer the analysis was carried out at two levels, overstory and plot level.

\section{Study area and field datasets}

The existence of field and contemporary radar data conditioned this study. Seven fires located on three continents (North America, Australia and Europe) were selected to represent a wide range of forest types (i.e., species and structures). At all locations fires affected both understory and overstory layers.

\section{Australia}

In Australia, the Kinglake fire complex affected approximately 285,200 ha encompassing three forest types. Since each forest type has potentially different responses to fire they were analyzed separately. Kinglake fire burned during the austral summer between February and March 2009. The area is dominated by mixed eucalyptus forests. According to the Department of Environment and Primary Industries (DEPI), Victoria, these forests are categorized within three main types: i) wet forest dominated by Eucalyptus regnans, ii) damp forests dominated by mixed eucalyptus species such as E. obliqua and E. radiata and, iii) forby forests dominated by E. obliqua, E. radiata and E. cypellocarpa (Cheal 2010). The average above ground biomass (AGB), diameter at breast height $(\mathrm{DBH})$, height $(\mathrm{H})$ and the maximum height for each forest types is provided in Table 1. Fedrigo et al. (2014) provided the values for the wet forest while for the remaining forest types information from unpublished field datasets was used. Within two months after the fire DEPI teams collected field estimates of severity using $30 \mathrm{~m}$ radius plots and a specific field protocol which provided information on the percentage of green, black and brown tree canopy for two vegetation strata through ocular estimations, tree height and char height (from clinometers), leaf fall cover, percentage of bare soil, the presence of epicormic growth, post-fire vegetation growth and plot slope and aspect. Using DEPI's field data we computed CBI-like scores for the two vegetation strata and a CBIlike score for the substrate. CBI at plot level was subsequently computed as the average score of these three strata. In total, 376 field plots were available for the analysis, 45 for the wet forest, 146 for the damp forest and 185 for the forby forest. Although DEPI collected information for over 700 plots we only used the plots located in the western part of the Kinglake fire perimeter. Such a selection was conditioned by the availability of L-band SAR data acquired under dry environmental conditions, the combination providing the highest sensitivity to fire severity (Tanase et al. 2010a).

\section{United States}

In the US, three fires located in California (Iron Complex affecting approximately 46,000 ha), Oregon (Rooster Rock affecting approximately 2,550 ha) and Washington (Columbia River Road affecting approximately 9,050 ha) were selected for this study. Iron Complex and Columbia River Road fires burnt in June and respectively August 2008 while Rooster Rock fire burnt in August 2010. In California, the forest affected by fire was dominated by a mix of softwood and hardwood western species. According to U.S. Forest Service Forest Inventory and 
Analysis (FIA) database, over $80 \%$ of the trees sampled within the fire perimeter belonged to Pseudotsuga menziesii (25\%), Arbutus sp. (13\%) or Quercus chrysolepis (44\%) species. In Oregon, the forest affected by fire was dominated by Pinus ponderosa, Pinus contorta and Pseudotsuga menziesii which represented about 60\% of the trees in the FIA database, with other coniferous species representing additional 20\% of the trees. In Washington State, the fire affected forest was also dominated by Pinus ponderosa, Pinus contorta, and Pseudotsuga menziesii which represented about $65 \%$ of the trees in the FIA database with other coniferous species representing additional $15 \%$ of the trees. Although the main species present within the fire perimeter at Rooster Rock and Columbia River Road were mostly the same we considered the two forests as different types due to the lower biomass level and the shorter, thinner trees present within the fire perimeter at Columbia River Road. FIA database provided information on forest type characteristics (plots sampled before fires) as shown in Table 1 (Miles 2014). Field estimates of fire severity were collected by the FIRE SEVerity (FIRESEV) teams within 10 to 15 months following the fires in $11 \mathrm{~m}$ radius plots. FIRESEV database includes information on plot location, tree species and canopy characteristics, CBI values for each strata as well as a composite CBI value for the entire plot and field photographs (Sikkink et al. 2013). The data was collected using a modified CBI field protocol (Dillon et al. 2011). For this study we have used the CBI values for the plot level (computed based on the overall average of all strata except for the minimum branch diameter) as well as the CBI values for the tallest tree strata available at each sampled location (computed for all elements except for the minimum branch diameter) considered as the top overstory layer having the most influence on the optical sensor reflectance and respectively radar backscatter. In addition to the FIRESEV plots, we have selected a series of random plots outside each fire perimeter to characterize unburnt forests. In total 52 plots were analyzed for the Iron Complex fire, 34 for the Rooster Rock fire and 36 for the Columbia River Road fire.

Europe

In Europe, three fires located in northeastern Spain were analyzed (Zuera, Aliaga and Los Olmos). The Zuera fire burned 2,200 ha in August 2008 while, the Aliaga and Los Olmos fires burned 9,000 and respectively 500 ha in July 2009. Since the main tree species present at each fire location was the same (i.e., Pinus halepensis) we considered a single forest type (i.e., Mediterranean pine forest) as being representative for all fires and extracted its characteristics (Table 1) from the third Spanish Forest National Inventory (FNI). Tanase et al. (2011) assessed fire severity in all these fires within two months after burn using the original CBI field protocol (Key and Benson 2006) on 15m radius plots located in areas of homogeneous forest structure and fire effects. The vegetation layers consisted of substrate, herbs and low shrubs less than $1 \mathrm{~m}$ tall, shrubs and trees up to $5 \mathrm{~m}$ tall (understory), and intermediate trees up to $20 \mathrm{~m}$ tall (overstory). In total, 44 plots were assessed at Aliaga fire, 32 at Los Olmos fire and 118 at the Zuera fire (Tanase et al. 2011).

The field protocols used in US (FIRESEV) and Australia (DEPI) differed with respect to the original CBI protocol (Key and Benson 2006) used by Tanase et al. (2011) at the European sites. In Australia, field operators did not record information on canopy mortality for the overstory strata, the understory strata comprised not only sub canopy trees bus also shrubs while for the substrate information on fuel consumption was absent. Therefore, although CBI scores computed for the tallest tree strata comprising the overstory layer is largely similar with what would have been obtained using the standard CBI field protocol (i.e., canopy mortality is largely incorporated by assessing the percentage of green, black and scorched canopy), for the remaining strata and therefore plot level CBI values might differ significantly when compared to the standard protocol. In the US, FIRESEV teams recorded most of the parameters defined by Key and Benson (2006) although their assessment might have been slightly different. Some parameters such as the percentage of torched and scorched canopy were recorded as one (i.e., Black/Brown) while new parameters were added (i.e., diameter of smallest branch left). Therefore small differences in the CBI scores for each strata when compared to the original CBI scores are likely. However, the qualitative nature of field severity estimation would most probably result in larger score differences when compared to using slightly different field protocols. Overall, one should remember the different field sampling when comparing results across study areas particularly at plot level and for the Australian forests.

\section{Remote sensing data}

For this study, the optical index selected for the analysis was the widely used dNBR computed from Landsat TM pre- and post-fire images. Data acquired by the Advanced Land Observing Satellite (ALOS) Phased Array type Lband Synthetic Aperture Radar (PALSAR) were used to derive the radar burn ratio (RBR), the ratio between the power of post- and pre-fire images for the cross-polarized (i.e., HV polarization) channel. Cross-polarized L-band data was selected since previous studies demonstrated its higher sensitivity to fire effects when compared to X- 
and C-band (Tanase et al. 2010a). RBR shows the magnitude of change in the radar signal and should be linearly related to the decrease (due to fire consumption) of vegetation scattering elements.

\section{Landsat data}

Two Landsat TM scenes were obtained from the U.S. Geological Survey (USGS) EarthExplorer (http://earthexplorer.usgs.gov) as higher level data products (i.e., surface reflectance) for each fire (Table 2). Except for Zuera, Landsat data were processed by USGS through the Level 1 Product Generation System (LPGS) and the Landsat Ecosystem Disturbance Adaptive Processing System (LEDAPS) which applies Moderate Resolution Imaging Spectroradiometer (MODIS) atmospheric correction routines to Level-1 Landsat data (Masek et al. 2006). The result is a Universal Transverse Mercator (UTM) Landsat surface reflectance product in GEOTIFF format at $30 \mathrm{~m}$ spatial resolution. For the Zuera fire the Landsat TM scenes were not available in the USGS database and were obtained through the Spanish Remote Sensing National Plan (PNT). These two Landsat scenes were geometrically rectified to the UTM projection using a linear polynomial model and incorporating information of the local topography within a previous study (Tanase et al. 2011). Ground control points were used to register each scene to high resolution orthophotos from the Spanish National Aerial Ortophoto Program (PNOA) with a root mean squared error (RMSE) of less than one pixel. The images underwent radiometric corrections to compensate for variation in sensor radiometric response, sun angle, sun azimuth, and topography using the Atmospheric/Topographic Correction for Mountainous Terrain package (ATCOR ${ }^{\circledR} 3$ ) implemented in ERDAS Imagine software. Atmospherically corrected images are needed for quantitative retrieval of land surface information since haze, clouds and shadows limit the effectiveness of remote sensing measurements (Chavez 1988; Liang et al. 2002).

The change detection approach conditioned satellite image selection due to the need of images with similar forest phenology (Key and Benson 2006). Such requirements are more stringent for deciduous vegetation due to senescence and for high latitudes due to the large variations in sun angle which may significantly bias fire severity estimation (Verbyla et al. 2008). We have minimized such effects by: i) using Landsat data acquired within less than a month at Columbia River Road (i.e., the site located at the highest latitude), ii) using data acquired within maximum two months for European sites which are located at lower latitudes and dominated by evergreen coniferous forests (i.e., less affected by changes in phenology or sun angle), and iii) by using data acquired roughly within the same month for the remaining sites (Table 2).

\section{SAR data}

For this study, between six and ten ALOS PALSAR fine beam dual (FBD) datasets acquired up to three years before and after the fire event were used for each fire (Table 3). The RBR for the cross-polarized channel (RBR $\left.\mathrm{RV}_{\mathrm{HV}}\right)$ was computed pixel wise as the average post-fire backscatter divided by the average pre-fire backscatter, except for Rooster Rock and Kinglake fires. For these fires, only one post-fire image was available or was acquired under dry conditions, and thus RBR was computed as the single date post-fire backscatter divided by the pre-fire average backscatter. Note that by using ratios the effect of topography on the radar signal is cancelled out and topographic normalization is not necessary.

For undisturbed forests, multi-temporal backscatter averages provide more accurate values by filtering out small temporal variations due to changing environmental conditions since forest structure is largely stable. In disturbed forests the backscatter signal is affected not only by the remaining vegetation (fire-impact dependent), but also by the forest recovery process (recruitment and regrowth). In coniferous species post-fire regrowth is slow. In Mediterranean pine forests seedlings reached only 15-20cm 39 months after fire (Thanos et al. 1996) while in temperate coniferous forests saplings reached $81 \mathrm{~cm} 11$ years after fire (Turner et al. 2004). Since L-band backscatter is mostly influenced by large vegetation components such as branches and trunks (Le Toan et al. 1992), low vegetation has a limited influence on the post-fire radar signal during the first years particularly since even at high fire severities most trees are left standing. For the Victorian Mountain ash (E. regnans) forests, the reported growth rates are much higher with sapling reaching 2-5 $\mathrm{m}$ in height after 3 years (Van Der Meer et al. 1999). However, for intermediate and low severity levels the unburnt vegetation is likely to mask the effects of recruitment and regrowth over the first years. Therefore, while a three year gap is unlikely to significantly affect post-fire backscatter values in slow growing forests the post-fire acquisition gap of radar datasets may need to be limited in faster growing forests (i.e., eucalypt) to avoid mixing the two concurring effects, namely fire impact and forest recovery. 
Previous research showed that rainfall has a significant effect on the radar signal in fire affected areas, with increased backscatter being attributed to decreased attenuation, strong trunk-ground interactions, and changes in soil moisture (Bourgeau-Chavez et al. 1994; Kasischke et al. 1994; Kasischke et al. 2011). Therefore, in this study preference was given to post-fire SAR datasets acquired under dry conditions to eliminate one of the most important source in backscatter variability (i.e., rainfall) which was previously associated to decreased sensitivity to fire severity (Tanase et al. 2010a). The SAR acquisition dates together with the environmental conditions at acquisition (i.e., precipitations and accumulated precipitations) are presented in Table 3. For the Kinglake fire most of the data sets were acquired under wet conditions with only one post-fire dataset (marked as dry date - dd) being acquired under dry conditions. For the remaining fires the SAR datasets were largely acquired under dry conditions.

All ALOS PALSAR datasets were received in single look complex (SLC) format. For this study, the SLC data acquired from the same path and frame at each location were co-registered using as master the first image of the data series and a cross-correlation algorithm (i.e., intensity tracking). After co-registration each image was multilooked in range (4) and azimuth (20) to obtain a ground pixel spacing around $60 \mathrm{~m}$. SAR intensity was transformed to the radar backscatter coefficient $\left(\sigma^{\circ}\right)$ after applying absolute calibration factors (Shimada et al. 2009). The final step was orthorectification to Universal Transverse Mercator (UTM) projection using a lookup table based on digital elevation models (DEM) and the orbital information of the SAR data and resampling to $30 \mathrm{~m}$ spatial resolution (Wegmüller et al. 2002). For the Australian fire the $30 \mathrm{~m}$ spacing Shuttle Radar Topography Mission (SRTM) digital elevation model (DEM) was used. The SRTM DEM was enhanced at Geoscience Australia by removing artifacts and noise present in the original SRTM data (Gallant et al. 2011). For the Spanish study area a 20 m DEM obtained from the regional government of Aragón was used while a 30 m DEM from the US National Elevation Dataset (NED) was used for the US fires (http://ned.usgs.gov).

\section{Methods}

Field data and remotely sensed indices are commonly related through empirical models when estimating fire severity (French et al. 2008). To select an appropriate model form, we first studied the relationships between CBI and remote sensing indices (i.e., $\mathrm{dNBR}$ and $\mathrm{RBR}_{\mathrm{HV}}$ ) using scatter plots. Subsequently, empirical models were developed to estimate fire severity at plot (CBI plot) and overstory (CBI overstory) levels. The models related CBI to remote sensing indices extracted for the pixel coordinates corresponding to the center of each field plot. The selection of linear models to represent the CBI-RBR relationship (Eq.1) was based on scatterplot analysis as explained in the next section. Since both field and remote sensing measurements are subject to errors we used reduced major axis regression when relating CBI and RBR (Quinn and Keough 2002). Past studies showed that non-linear models might be needed to fully capture the dNBR-CBI relationship (French et al. 2008). Such nonlinear relationships are well documented, with two model forms usually being parameterized for fire severity estimation, i.e., second order polynomial or saturated growth (Wimberly and Reilly 2007; Hall et al. 2008). Since previous studies showed relatively small differences between these two model forms with respect to the estimation error (Tanase et al. 2011) the former model form was preferred (Eq.2) due to its simplicity when adding new independent variables (i.e., $\mathrm{RBR}_{\mathrm{HV}}$ ) for fire severity estimation from multiple sensors. The joint use of $\mathrm{RBR}_{\mathrm{HV}}$ and dNBR was studied using an additive model (Eq.3) that combined the two functional terms to preserve the underlying relationship between each variable and the CBI (Burnham and Anderson 2002). Modelling was carried out for each individual fire as well as by pooling the datasets for coniferous (i.e., Aliaga, Los Olmos, Columbia River Road, Rooster Rock and Zuera) and eucalypt (i.e., Damp, Forby, and Wet) dominated forests. The pooled analysis was carried out to ascertain the loss in accuracy when using a single empirical model over wide areas to estimate fire severity.

$$
\begin{aligned}
& \mathrm{CBI}=\mathrm{a}+\mathrm{b} * \mathrm{RBR}_{\mathrm{HV}} \\
& \mathrm{CBI}=\mathrm{a}+\mathrm{b} * \mathrm{dNBR}+\mathrm{c} * \mathrm{dNBR}^{2} \\
& \mathrm{CBI}=\mathrm{a}+\mathrm{b} * \mathrm{dNBR}+\mathrm{c} * \mathrm{dNBR}^{2}+\mathrm{d} * \mathrm{RBR}_{\mathrm{HV}}
\end{aligned}
$$

where: CBI -fire severity at plot or overstory level;

$\mathrm{RBR}_{\mathrm{HV}}$ - Radar Burn Ratio (HV polarization);

dNBR - differenced Normalized Burn Ratio;

a, b, c, d - model coefficients. 
Cross-validation techniques are often used to compare the performance of different predictive models (Hall et al. 2008; Tanase et al. 2011). Due to the reduced number of field samples for most fires, cross-validation was based on leave-one-out method. Through an iterative process each sample was removed from the training dataset when calibrating the regression model and subsequently its difference with the modeled value was computed. These differences were used to compute the root mean squared error (RMSE) as the root of the average squared difference between the observed and the predicted values obtained during the iterative process. The correlation between predicted and observed values (r) was also computed based on the set aside samples and their predicted value (i.e., from the particular model iteration). In addition, the coefficient of determination $\left(\mathrm{R}^{2}\right)$ computed using all available samples was used as to assess the fit. The performance of each model was also tested using the Bayesian information criterion (BIC). Models with lower BIC values provide a better prediction of the characteristic of interest (Schwarz 1978).

To test the classification accuracy of the derived thematic maps the continuous we reclassified the CBI interval into four classes: unburnt $(\mathrm{CBI}=0)$, low severity $(0<\mathrm{CBI} \leq 1)$, medium severity $(1<\mathrm{CBI} \leq 2)$, and high severity $(\mathrm{CBI}>2)$. Due to the variety of needs and interpretations it is difficult to specify a single, all-purpose measure of classification accuracy (Foody 2002). In addition, different measures are sensitive to different features and may lead to conflicting results, and therefore no one measure is universally accepted (Stehman 1997). Some of the widely used accuracy metrics are based on confusion matrices with numerous studies using the percentage of cases correctly allocated (i.e., overall accuracy). In this study, the overall accuracy was used to assess the agreement between observed and predicted fire severity. Additionally, the percentage of misclassified plots was computed. A plot was considered misclassified when its predicted severity disagreed with the observed severity by more than one class with (i.e., plots falling into adjacent severity classes were not considered a serious deviation from truth).

\section{Results}

For $\mathrm{RBR}_{\mathrm{HV}}$ we observed linear relationships with fire severity for both plot and overstory levels with a polynomial model form providing only negligible increase of the coefficient of determination and leaving estimation error practically identical (Fig. 2, upper panels). For dNBR a non-linear relationship with fire severity was observed for both severity levels (Fig.2, lower panels) as expected. Modeling results (i.e., fit and error metrics) are provided in Table 4 for each individual fire and cumulatively for the main forest types (coniferous and eucalypt). Selected fit $\left(\mathrm{R}^{2}\right.$ and $\mathrm{r}$ ) and error metrics (RMSE and overall accuracy) are displayed graphically for an easier interpretation in Fig 3. From Table 4 and Fig. 3 it is evident that, fire severity estimation was more accurate when using optical based indices when compared to radar based indices at both plot (Fig. 3a) and overstory (Fig. 3b) levels. Over all fires, dNBR based RMSE was on average 0.2 (i.e., about $7 \%$ of the CBI range) lower when compared to RBR $\mathrm{HV}_{\mathrm{HV}}$. However, modeling results varied among forest types depending on their above ground biomass levels. The greatest differences in fit and error metrics between $\mathrm{dNBR}$ and $\mathrm{RBR}_{\mathrm{HV}}$ were observed for the forest types with above ground biomass values considerably higher than the L-band saturation limit of approximately $100 \mathrm{t} \mathrm{ha}^{-1}$ (Dobson et al. 1992). On average, across those forests (Kinglake and Iron Complex fires), the estimation accuracy (RMSE) using $\mathrm{RBR}_{\mathrm{HV}}$ was about 0.3 points lower (i.e., $10 \%$ of the CBI range) when compared to dNBR (Table 4) with the maximum difference (0.5 points) being recorded for the mixed species forest (Iron Complex fire). For high biomass forests, the overall accuracy was $17 \%$ lower for $\mathrm{RBR}_{\mathrm{HV}}$ when compared to dNBR. For coniferous forests (i.e., AGB values below the L-band saturation limit), the overall difference between radar and optical based estimates was less accentuated with RMSE and overall accuracy being on average 0.16 and respectively $6 \%$ lower when compared to dNBR. Comparing BIC values for dNBR and RBR $\mathrm{HV}_{\mathrm{H}}$ models showed small $(<5)$ differences for some individual fires (Rooster Rock, Columbia River Road and Zuera) and for the pooled coniferous data suggesting similar predictive powers. For the remaining fires and pooled eucalypt data BIC values were much smaller when using dNBR. The overall accuracy for the pooled datasets was above $70 \%$ for both overstory and plot levels (Table 4) with the lowest omission and commission errors being observed for the high severity class (Table 5). For the remaining classes, omission and omission errors although frequent, were mostly restricted to one class differences.

When comparing fire severity estimation for plot and overstory levels for the same remote sensing index the overall accuracy as well as model fit metrics ( $\mathrm{R}^{2}$ and $\mathrm{r}$ ), were usually higher for the overstory level. This was expected since both sensor types are mostly influenced by the upper canopy layer whose severity is not always linked to the understory/substrate fire severity (i.e., the estimation accuracy is reduced by including strata which have a reduced influence on the optical or radar measurements). Comparing dNBR with the joint use of optical and radar indices (dNBR and $\mathrm{RBR}_{\mathrm{HV}}$ ) indicated better results for the latter (Fig. 3c and Fig. 3d). On average, for all forest types the 
joint use of both sensors increased model fit $\left(\mathrm{R}^{2}\right)$ by 0.04 and reduced RMSE by 0.04 while maintaining the same overall accuracy when compared to only using dNBR (Table 4). Notice that for some fires (i.e., Los Olmos, Rooster Rock and Columbia River Road) the RMSE decreased by about 0.1 when jointly using dNBR and RBR HV. $_{\text {. }}$ Such improved fit metrics translated into fewer misclassification errors when differentiating forests not affected by fires (Fig.4). BIC values also showed that for about $70 \%$ of the cases the joint use of optical and radar data provided better predictions when compared to using only optical data.

\section{Discussion}

Fire severity estimation based on methods using pre-determined thresholds (e.g., Monitoring Trends in Burn Severity (Eidenshink et al. 2007)) do not always perform adequately, particularly for ecotypes with few ground observations (French et al. 2008; Kolden et al. 2012; Boschetti et al. 2015). Therefore, in this study empirical modeling was used to model fire severity based on reference field data. The results indicated that overall, SAR sensors provide estimation accuracies largely comparable to optical sensors when used in forests with biomass below SAR saturation. The accuracy of $\mathrm{RBR}_{\mathrm{HV}}$ was significantly reduced in forests with high aboveground biomass. SAR signal is directly influenced by forest structure, and so the analysis of pre-post fire datasets can inform of fire severity as it reflects changes in structure associated to fire. In the particular case of L-band wavelength, a large part of the scattering comes from branches and trunks (McDonald et al. 1990; Le Toan et al. 1992). However, even the most severe fires will often consume just tree leaves and branches, leaving dead stems standing on site. This means that differences in total scattering when compared to pre-fire levels (i.e., the degree of change) may not vary much across severity classes as scattering from tree trunks may largely replace scattering from branches particularly for high biomass forests. L-band saturation limit (i.e., $100 \mathrm{t} \mathrm{ha}^{-1}$ ) compromised the strength of the relationship between the SAR signal and biomass in such forests, thus hindering an accurate estimation of changes in SAR scattering. For forests with AGB levels below this threshold (i.e., coniferous forest), the results were largely comparable with those obtained from the optical based indices. Therefore, it is expected that SAR sensors with longer wavelengths and thus higher saturation limits (e.g., P-band from the future BIOMASS mission) would provide more accurate results in forests with high levels of biomass. It is also important to note that field reference data were collected using an index (i.e., CBI) specifically designed with optical datasets in mind which largely assesses fire severity from a 'color' perspective: percentage of green, black or brown vegetation. Since SAR data are sensitive to the amount of vegetation elements consumed by fire, there is potential in improving the relationship between RBR and fire severity by collecting information on branch/stems consumption within existing or new field protocols. Nevertheless, the need for multiple pre- and post-fire datasets, the inherent complexity of SAR data processing/analysis and potential data costs make RBR valuable mostly for specific conditions (e.g., persistent cloud cover, high solar elevation angles, etc.) where optical sensors are less sensitive. The higher estimation accuracies obtained from optical based indices, particularly for forests with large AGB values, free data access to the extensive Landsat archive, compatible future missions, simpler processing and lower data needs, make the use of dNBR a simpler proposition for estimating fire severity when cloud cover or solar elevation are not an issue.

The joint use of optical and radar based indices improved the estimation accuracy for most fires as shown by the lower BIC values. Particularly, SAR data provided useful information for a more accurate classification of areas not affected by fires or affected with low severity. Misclassification errors of unburnt areas decreased by about $3 \%$ and $7 \%$ for coniferous and respectively eucalypt forests (average values for plot and overstory). Such areas have a significant ecological importance by providing refugia and seed sources for forest regeneration (Kolden et al. 2012). The results also showed a higher accuracy when estimating overstory severity compared to plot severity. Increasing fire severity translates into additional vegetation elements being altered and/or consumed, which constitutes the basis of remote sensing sensors sensitivity to fire effects. Such effects are comparable over forest types, and the use of pre- and post-fire datasets provides a means to derive changes caused by fires with respect to local pre-fire vegetation conditions. Changes in forest canopy conditions directly influence reflectance or scattering while the influence of a changing understory depends on forest canopy cover and sensor since optical sensors will not see through a closed canopy and radar waves penetrate forest canopies only to a certain extent, wavelength depending. Therefore, remote sensing indices are likely to produce stronger relationships for the overstory layer, particularly when fire effects over various forest strata are not correlated. While optical indices were more accurately related to plot fire severity, RBR values computed from future P-band sensors like BIOMASS should be more closely related to the understory fire effects due to the higher wave penetration. This might considerably increase fire severity estimation accuracy at plot level and might provide stronger relationships 
between RBR and understory fire effects, which is particularly important when estimating the effects of low intensity fires such as prescribed burning.

\section{Conclusions}

This study analyzed the benefit of using passive (optical) or active (radar) remote sensing sensors as well as their synergy for fire severity estimation. While a radar based index showed largely comparable estimation accuracies when compared to optical based indices for forests with biomass levels below the L-band saturation point, for high biomass forests optical indices provided considerably better results. Nevertheless, future P-band space borne SAR sensors should allow for improved estimation accuracy in high biomass forests. The joint use of radar and optical based indices allowed for marginal increases in the estimation accuracy and reduced misclassification errors for unburnt areas. While the use of optical based indices is certainly a simpler proposition for fire severity estimation in most environments, radar based indices have the advantage of not depending on cloud cover and sun elevation angle which makes them relevant in certain environments such as tropical or boreal. However, the user needs to consider SAR saturation with increasing biomass when selecting the adequate radar wavelength.

\section{Acknowledgments}

This work was funded by the University of Melbourne through an Early Career Research Grant (ECR 602155). ALOS PALSAR datasets were provided by the Japanese Space Agency within the 4th ALOS Research Announcement (PI 1091). The two anonymous reviewers are also acknowledged for their useful suggestions which significantly improved the original manuscript.

\section{References}

Allen JL, Sorbel B (2008) Assessing the differenced Normalized Burn Ratio's ability to map burn severity in the boreal forest and tundra ecosystems of Alaska's national parks. International Journal of Wildland Fire 17, 463475.

Benyon RG, Lane PNJ (2013) Ground and satellite-based assessments of wet eucalypt forest survival and regeneration for predicting long-term hydrological responses to a large wildfire. Forest Ecology and Management 294, 197-207.

Boer MM, Macfarlane C, Norris J, Sadler RJ, Wallace J, Grierson PF (2008) Mapping burned areas and burn severity patterns in SW Australian eucalypt forest using remotely-sensed changes in leaf area index. Remote Sensing of Environment 112, 4358-4369.

Bourgeau-Chavez LL, Harrell PA, Kasischke ES, French NHF (1997) The detection and mapping of Alaskan wildfires using a spaceborne imaging radar system. International Journal of Remote Sensing 18, 355-373.

Bourgeau-Chavez LL, Kasischke ES, Brunzell S, Mudd JP (2002) Mapping fire scars in global boreal forests using imaging radar data. International Journal of Remote Sensing 23, 4211-4234.

Bourgeau-Chavez LL, Kasischke ES, French NHF, Szeto LH, Kherkher CM (1994) 'Using ERS-1 SAR Imagery to Monitor Variations in Burn Severity in an Alaskan Fire-Disturbed Boreal Forest Ecosystem, Geoscience and Remote Sensing Symposium, 1994. IGARSS '04. Proceedings.' Pasadena, California, Aug.1994. IEEE International.

Burnham KP, Anderson DR (2002) Model selection and multimodel inference: a practical information-theoretic approach. (Springer Science \& Business Media). 
Chavez PS (1988) An improved dark-object subtraction technique for atmospheric scattering correction of multispectral data. Remote Sensing of Environment 24, 459-479.

Cheal DC (2010) Growth Stages and Tolerable Fire Intervals for Victoria's Native Vegetation Datasets. Department of Sustainability and Environment, Victoria, Melbourne, Australia.

Chuvieco E, Riaño D, Danson FM, Martín P (2006) Use of a radiative transfer model to simulate the postfire spectral response to burn severity. Journal of Geophysical Research 111, 1-15.

Cocke AE, Fule PZ, Crouse JE (2005) Comparison of burn severity assessments using differenced normalized burn ratio and ground data. International Journal of Wildland Fire 14, 189-198.

de Santis A, Chuvieco E (2009) GeoCBI: A modified version of the Composite Burn Index to estimate burn severity for remote sensing applications. Remote Sensing of Environment 113, 554-562.

Dillon GK, Morgan P, Holden ZA (2011) Mapping the Potential for Severe Fire in the Western United States Fire Management Today 71, 1-28.

Dobson MC, Ulaby T, Le Toan T, Beaudoin A, Kasischke ES (1992) Dependence of radar backscatter on coniferous forest biomass. IEEE Transactions on Geoscience and Remote Sensing 30 412-415.

Eidenshink J, Schwind B, Brewer K, Zhu Z, Quayle B, Howard S (2007) A project for monitoring trends in burn severity. Fire Ecology 3, 3-21.

Epting J, Verbyla D, Sorbel B (2005) Evaluation of remotely sensed indices for assessing burn severity in interior Alaska using Landsat TM and ETM+. Remote Sensing of Environment 96, 328-339.

Fedrigo M, Kasel S, Bennett LT, Roxburgh SH, Nitschke CR (2014) Carbon stocks in temperate forests of southeastern Australia reflect large tree distribution and edaphic conditions. Forest Ecology and Management 334, 129143.

Ferrazzoli P, Paloscia S, Pampaloni P, Schiavon G, Sigismondi S, Solimini D (1997) The Potential of Multifrequency Polarimetric SAR in Assessing Agricultural and Arboreous Biomass. IEEE Transactions on Geoscience and Remote Sensing 35, 5-17.

Foody GM (2002) Status of land cover classification accuracy assessment. Remote Sensing of Environment 80, 185-201.

French NHF, Kasischke ES, Hall RJ, Murphy KA, Verbyla DL, Hoy EE, Allen JL (2008) Using Landsat data to assess fire and burn severity in the North American boreal forest region: an overview and summary of results International Journal of Wildland Fire 17, 443-462.

Gallant JC, Dowling TI, Read AM, Wilson N, Tickle P, Inskeep C (2011) 1 second SRTM Derived Digital Elevation Models User Guide. Geoscience Australia, National Earth Observation Group, Environmental 
Geoscience Division, Geoscience Australia GPO Box 378 Canberra ACT 2601. Available at www.ga.gov.au/topographic-mapping/digital-elevation-data.html.

Hall RJ, Freeburn JT, de Groot WJ, Pritchard JM, Lynham TJ, Landry R (2008) Remote sensing of burn severity: experience from western Canada boreal fires. International Journal of Wildland Fire 17,

Henry MC, Hope AS (1998) Monitoring post-burn recovery of chaparral vegetation in southern California using multi-temporal satellite data. International Journal of Remote Sensing 19, 3097-3107.

Heward H, Smith AMS, Roy DP, Tinkham WT, Hoffman CM, Morgan P, Lannom KO (2013) Is burn severity related to fire intensity? Observations from landscape scale remote sensing. International Journal of Wildland Fire 22, 910-918.

Holden ZA, Morgan P, Smith AMS, Vierling L (2010) Beyond Landsat: a comparison of four satellite sensors for detecting burn severity in ponderosa pine forests of the Gila Wilderness, NM, USA. International Journal of Wildland Fire 19, 449-458.

Hoy EE, French NHF, Turetsky MR, Trigg SN, Kasischke ES (2008) Evaluating the potential of Landsat TM/ETM+ imagery for assessing fire severity in Alaskan black spruce forests. International Journal of Wildland Fire 17, 500-514.

Kasischke E, Hoy EE (2012) Controls on carbon consumption during Alaskan wildland fires. Global Change Biology 18, 685-699.

Kasischke ES, Bourgeau-Chavez LL, French NHF (1994) Observations of Variations in ERS-1 SAR Image Intensity Associated with Forest Fires in Alaska. IEEE Transactions on Geoscience and Remote Sensing 32, 206210.

Kasischke ES, Bourgeau-Chavez LL, French NHF, Harrell P, Christensen NL (1992) Initial observations on using SAR to monitor wildfire scars in boreal forests. International Journal of Remote Sensing 13, 3495-3501.

Kasischke ES, Tanase MA, Bourgeau-Chavez LL, Borr M (2011) Soil moisture limitations on monitoring boreal forest regrowth using spaceborne L-band SAR data. Remote Sensing of Environment 115, 227-232.

Kasischke ES, Turetsky MR, Ottmar RD, French NHF, Hoy EE, Kane ES (2008) Evaluation of the composite burn index for assessing fire severity in Alaskan black spruce forests. International Journal of Wildland Fire 17, 515-526.

Keeley JE (2009) Fire intensity, fire severity and burn severity: a brief review and suggested usage. International Journal of Wildland Fire 18, 116-126.

Keeley JE, Brennan T, Pfaff AH (2008) Fire Severity and Ecosystem Responses Following Crown Fires in California Shrublands. Ecological Applications 18, 1530-1546. 
Key CH (2006) Ecological and sampling constraints on defining landscape fire severity. Fire Ecology 2, 34-59.

Key CH, Benson NC (2006) Landscape assessment (LA) Sampling and Analysis Methods. U.S. Department of Agriculture, Forest Service, Rocky Mountain Research Station, Gen. Tech. Rep. RMRS-GTR-164-CD, Fort Collins, CO.

Kolden CA, Lutz JA, Key CH, Kane JT, Wagtendonk JWv (2012) Mapped versus actual burned area within wildfire perimeters: Characterizing the unburned. Forest Ecology and Management 286, 38-47.

Landmann T (2003) Characterizing sub-pixel Landsat ETM+ fire severity on experimental fires in the Kruger National Park, South Africa. South African Journal of Science 99, 357-359.

Le Toan T, Beaudoin A, Guyon D (1992) Relating forest biomass to SAR data. IEEE Transactions on Geoscience and Remote Sensing 30, 403-411.

Lentile LB, Holden ZA, Smith AMS, Falkowski MJ, Hudak AT, Morgan P, Lewis SA, Gessler PE, Benson NC (2006) Remote sensing techniques to assess active fire characteristics and post-fire effects. International Journal of Wildland Fire 15, 319-345.

Liang S, Fang H, Morisette JT, Chen M, Shuey CJ, Walthall CL, Daughtry CST (2002) Atmospheric Correction of Landsat ETM+ Land Surface Imagery: II. Validation and Applications. IEEE Transactions on Geoscience and Remote Sensing 40, 2736-2746.

López-García MJ, Caselles V (1991) Mapping burns and natural reforestation using Thematic Mapper data. Geocarta International 61, 31-37.

Masek JG, Vermote EF, Saleous NE, Wolfe R, Hall FG, Huemmrich KF, Gao F, Kutler J, Lim T-K (2006) A Landsat Surface Reflectance Dataset for North America, 1990-2000. IEEE Transactions on Geoscience and Remote Sensing Letters 3, 68-72.

McDonald KC, Dobson MC, Ulaby FT (1990) Using MIMICS to Model L-Band Multitemporal Backscatter Walnut Orchard. IEEE Transactions on Geoscience and Remote Sensing 28, 477-491.

Menges CH, Bartolo RE, Bell D, Hill GJE (2004) The effect of savanna fires on SAR backscatter in northern Australia. International Journal of Remote Sensing 25, 4857-4871.

Miles PD, 2014. Forest Inventory EVALIDator web-application version 1.6.0.01. US Department of Agriculture, Forest Service, Northern Research Station, St. Paul, MN. Available only on internet at http://apps.fs.fed.us/ Evalidator/evalidator.jsp. Last accessed June $3^{\text {rd }} 2015$.

Miller JD, Thode AE (2007) Quantifying burn severity in a heterogeneous landscape with a relative version of the delta Normalized Burn Ratio (dNBR). Remote Sensing of Environment 109, 66-80. 
Miller JD, Yool SR (2002) Mapping forest post-fire canopy consumption in several overstory types using multitemporal Landsat TM and ETM data. Remote Sensing of Environment 82, 481-496.

Montealegre AL, Lamelas MT, Tanase MA, de la Riva J (2014) Forest Fire Severity Assessment Using ALS Data in a Mediterranean Environment. Remote Sensing 6, 4240-4265.

Murphy KA, Reynolds JH, Koltun JM (2008) Evaluating the ability of the differenced Normalized Burn Ratio (dNBR) to predict ecologically significant burn severity in Alaskan boreal forests. International Journal of Wildland Fire 17, 490-499.

Quinn GP, Keough MJ (2002) 'Experimental Design and Data Analysis for Biologists.' (Cambridge University Press: Cambridge, UK)

Riaño D, Chuvieco E, Ustin S, Zomer R, Dennison P, Roberts D, Salas J (2002) Assessment of vegetation regeneration after fire through multitemporal analysis of AVIRIS images in the Santa Monica Mountains. Remote Sensing of Environment 79, 60-71.

Rignot E, Despain DG, Holecz F (1999) 'The 1988 Yellowstone fires observed by imaging radars, Proceedings of the Joint Fire Sciences Conference and Workshop.'

Roy DP, Boschetti L, Trigg SN (2006) Remote Sensing of Fire Severity: Assessing the Performance of the Normalized Burn Ratio. IEEE Transactions on Geoscience and Remote Sensing Letters 1-5.

Saich P, Rees WG, Borgeaud M (1999) Mapping and Monitoring Forest Destruction in the Kola Peninsula Using the ERS SAR. IEEE Transactions on Geoscience and Remote Sensing 2098.

Schwarz GE (1978) Estimating the dimension of a model. Annals of Statistics 6, 461-464.

Shimada M, Isoguchi O, Tadono T, Isono K (2009) PALSAR Radiometric and Geometric Calibration. IEEE Transactions on Geoscience and Remote Sensing 47, 3915-3932.

Siegert F, Hoffmann AA (2000) The 1998 Forest Fires in East Kalimantan (Indonesia): A Quantitative Evaluation Using High Resolution, Multitemporal ERS-2 SAR Images and NOAA-AVHRR Hotspot Data. Remote Sensing of Environment 72, 64-77.

Siegert F, Nakayama M (2000) Comparison of ERS-2 and JERS for fire impact assessment in tropical rainforests. In 'Geoscience and Remote Sensing Symposium, 2000. IGARSS '00. Proceedings. 2000 IEEE International Honolulu, HI, USA'. Volume 6 pp. 2709-2711.

Siegert F, Rucker G, Hoffman A (1999) 'Evaluation of the 1998 Forest Fires in East-Kalimantan (Indonesia) Using NOAA-AVHRR hotspot Data and Multitemporal ERS-2 SAR images, Geoscience and Remote Sensing Symposium, 1999. IGARSS '99. Proceedings. 1999 IEEE International ' Hamburg, Germany. 
Sikkink PG, Dillon GK, Keane RE, Morgan P, Karau EC, Holden ZA, Silverstein RP, 2013. Composite Burn Index (CBI) data and field photos collected for the FIRESEV project, western United States. Fort Collins, CO.

Smith AMS, Wooster MJ, Drake NA, Dipotso FM, Falkowski MJ, Hudak AT (2005) Testing the potential of multi-spectral remote sensing for retrospectively estimating fire severity in African Savannahs. Remote Sensing of Environment 97, 92-115.

Sparks AM, Boschetti L, Smith AMS, Tinkham WT, Lannom KO, Newingham BA (2015) An accuracy assessment of the MTBS burned area product for shrub-steppe fires in the northern Great Basin, United States. International Journal of Wildland Fire 24, 70-78.

Stehman SV (1997) Selecting and Interpreting Measures of Thematic Classification Accuracy. Remote Sensing of Environment 62,

Tanase MA, de la Riva J, Pérez-Cabello F (2011) Estimating burn severity at the regional level using optically based indices. Canadian Journal of Forest Research 41, 863-872.

Tanase MA, de la Riva J, Santoro M, Le Toan T, Perez-Cabello F (2010a) Sensitivity of X-, C- and L-band SAR backscatter to fire severity in mediterranean pine forests. IEEE Transactions on Geoscience and Remote Sensing 48, 3663-3675.

Tanase MA, Santoro M, Aponte C, de la Riva J (2014) Polarimetric Properties of Burned Forest Areas at C- and L-Band. IEEE Journal of Selected Topics in Applied Earth Observation and Remote Sensing 7, 267-276.

Tanase MA, Santoro M, de la Riva J, Kasischke E, Korets MA (2010b) 'L-band SAR backscatter prospects for burn severity estimation in boreal forests, ESA Living Planet Symposium.' Bergen, Norway. (ESA Publications Division:

Tanase MA, Santoro M, Wegmüller U, de la Riva J, Perez-Cabello F (2010c) Properties of X-, C- and L-band repeat-pass interferometric SAR coherence in Mediterranean pine forests affected by fires. Remote Sensing of Environment 114, 2182-2194.

Thanos CA, Daskalakou E, Nikolaidou S (1996) Early post-fire regeneration of a Pinus hálepensis forest on Mount Parnis, Greece. Journal of Vegetation Science 7, 273-280.

Turner MG, Tinker DB, Romme WH, Kashian DM, Litton CM (2004) Landscape Patterns of Sapling Density, Leaf Area, and Aboveground Net Primary Production in Postfire Lodgepole Pine Forests, Yellowstone National Park (USA). Ecosystems 7, 751-775.

Van Der Meer PJ, Dignan P, Saveneh AG (1999) Effect of gap size on seedling establishment, growth and survival at three years in mountain ash (Eucalyptus regnans F. Muell.) forest in Victoria, Australia. Forest Ecology and Management 117, 33-42.

Van Der Werf GR, Randerson JT, Giglio L, Collatz GJ, Kasibhatla PS, Arellano AF (2006) Interannual variability in global biomass burning emissions from 1997 to 2004. Atmospheric Chemistry and Physics 6, 3423-3441. 
Van Wagtendonk JW, Root RR, Key CH (2004) Comparison of AVIRIS and Landsat ETM+ detection capabilities for burn severity. Remote Sensing of Environment 92, 397-408.

Verbyla DL, Kasischke ES, Hoy EE (2008) Seasonal and topographic effects on estimating fire severity from Landsat TM/ETM+ data International Journal of Wildland Fire 17, 527-534.

Viedma, Melia J, Segarra D, Garcia-Haro J (1997) Modeling Rates of Ecosystem Recovery after Fires by Using Landsat TM Data. Remote Sensing of Environment 61, 383-398.

Wang C, Glenn NF (2009) Estimation of fire severity using pre- and post-fire LiDAR data in sagebrush steppe rangelands. International Journal of Wildland Fire 18, 848-856.

Wegmüller U, Werner C, Strozzi T, Wiesmann A (2002) Automated and precise image registration procedures. In 'Analysis of multi-temporal remote sensing images.' (Eds L Bruzzone, P Smits.) Vol. 2 pp. 37-49. (World Scientific 2002: Singapore)

Wimberly MC, Reilly MJ (2007) Assessment of fire severity and species diversity in the southern Appalachians using Landsat TM and ETM+ imagery. Remote Sensing of Environment 108, 189-197. 

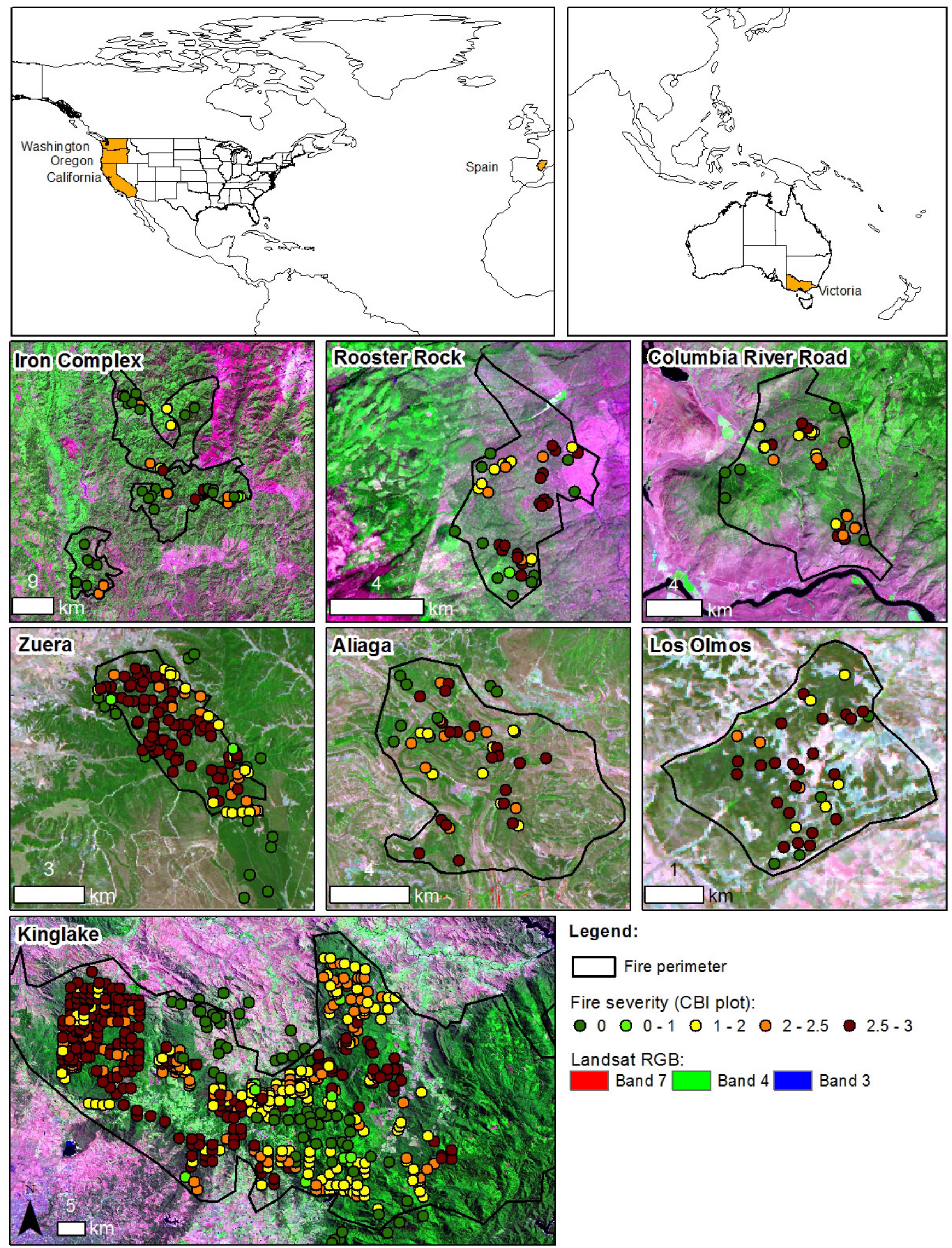

Legend:

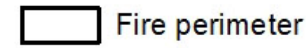

Fire severity ( $\mathrm{CBI}$ plot):

○ 0 ○ $0-1$ - 1 - 2 ○ $2-2.5 \bigcirc 2.5-3$

Landsat RGB:

Band $7 \square$ Band $4 \square$ Band 3

Fig. 1. Location of the studied fires together with the CBI field plots overlaid on pre-fire Landsat TM images 

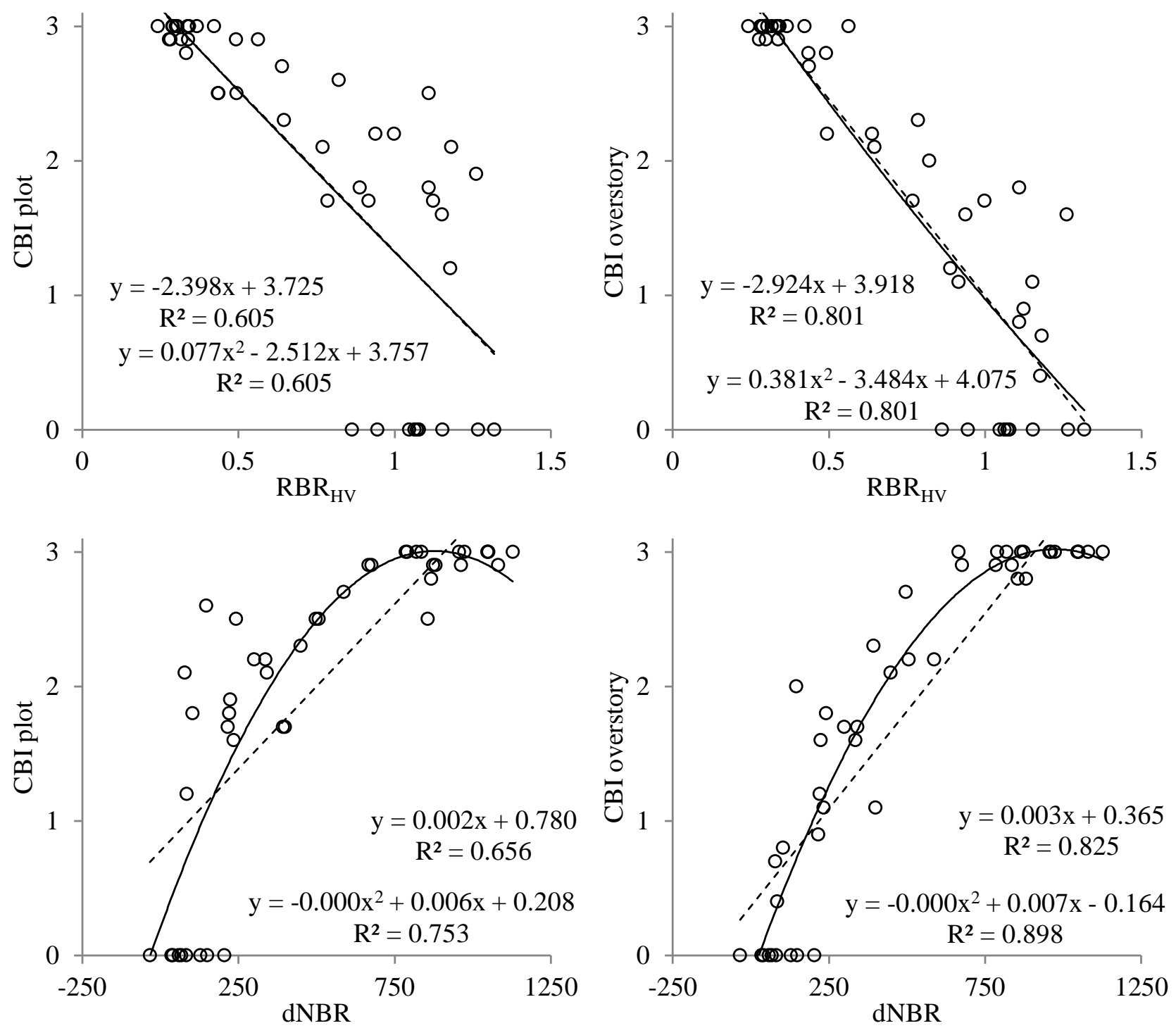

Fig. 2. Example of the relationships between remote sensing indices and field estimated fire severity at plot and overstory levels (Aliaga fire). Linear (dotted line) and quadratic (line) models were fitted to data. $\mathrm{RBR}_{\mathrm{HV}}$ - Radar Burn Ratio (HV polarization), dNBR - differenced Normalized Burn Ratio and CBI - Composite Burn Index. 

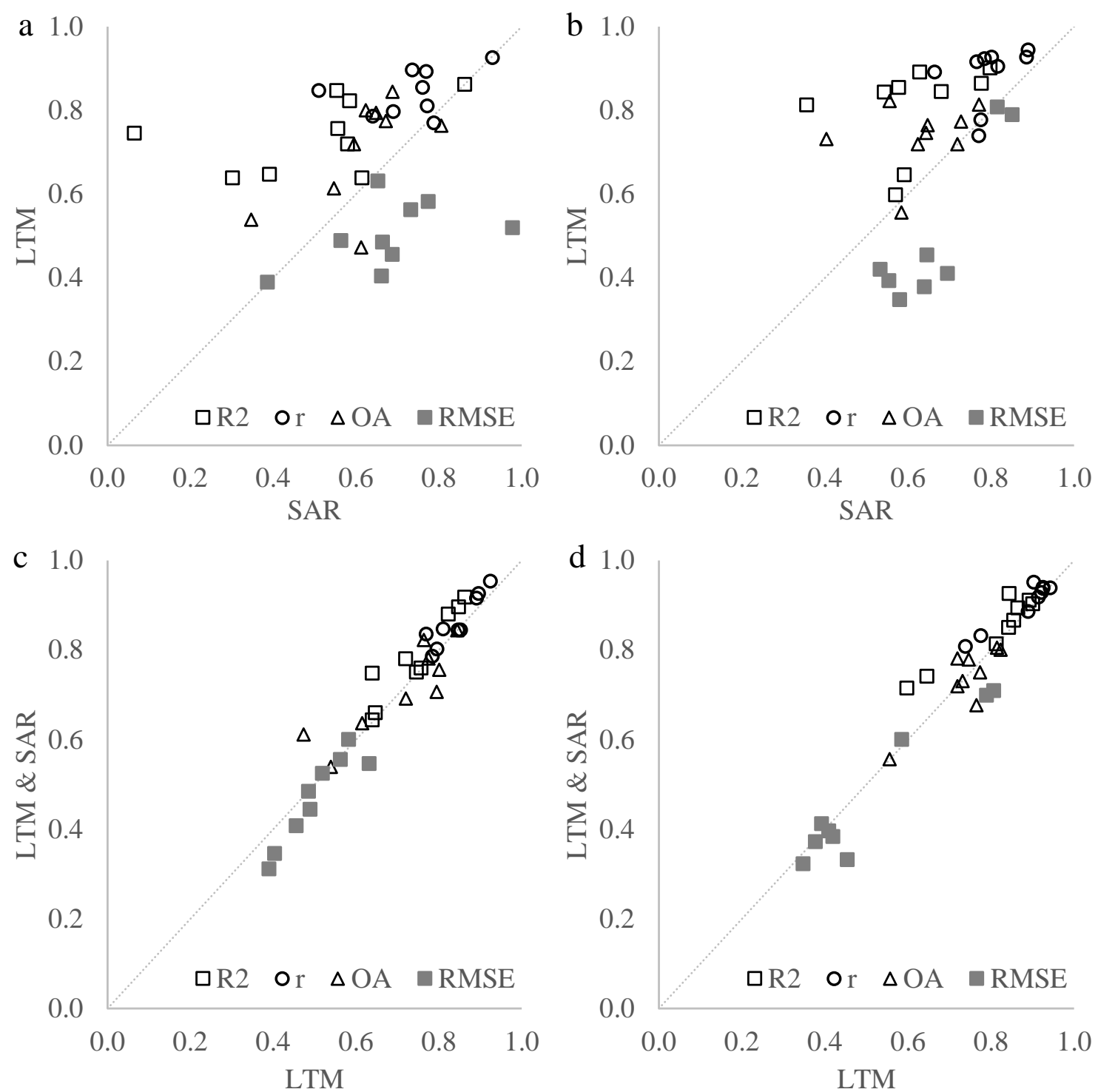

Fig. 3. Comparison of fire severity estimation error (RMSE), overall accuracy (OA, scaled by 1/100) and model goodness of fit $\left(\mathrm{R}^{2}\right.$ and $\mathrm{r}$ ) for all nine fires. Left column show values for plot level severity while right column

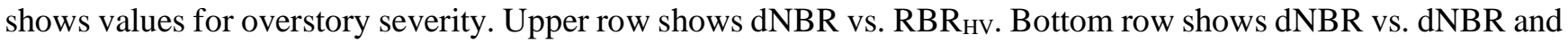
$\mathrm{RBR}_{\mathrm{HV}}$. The higher the value the better (hollow markers) the lower the value the better (filled markers). $\mathrm{R}^{2}-$ model coefficient of determination, $\mathrm{r}$ - correlation between observed and predicted values, RMSE - Root Mean Squared Error, $\mathrm{RBR}_{\mathrm{HV}}$ - Radar Burn Ratio (HV polarization), dNBR - differenced Normalized Burn Ratio, LTM - Landsat TM, SAR- Synthetic Aperture Radar. 


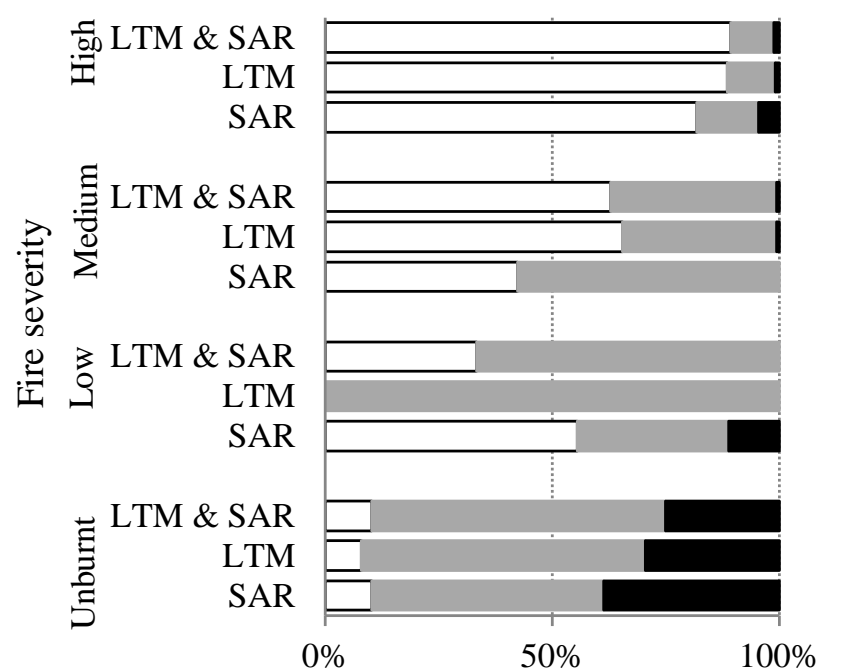

$\square$ Correct $\square$ class difference $\quad$ Missclasified

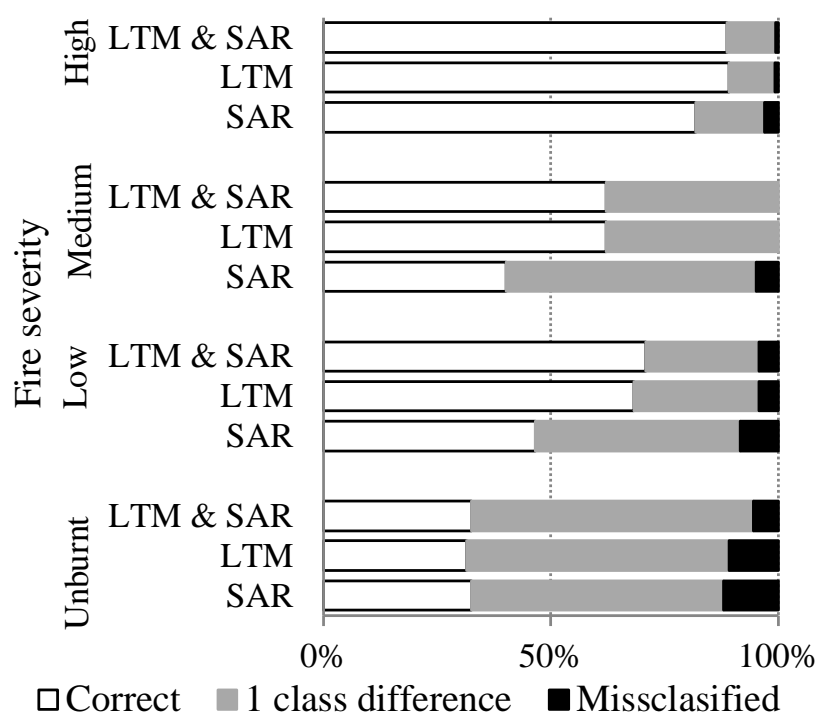

Fig. 4. Distribution of classification results for CBI plot (left column) and CBI overstory (right column). LTM Landsat TM, SAR- Synthetic Aperture Radar. Pooled results for all fires. 
Table 1 Forest type characteristics. AGB - Above Ground Biomass, DBH - Diameter at Breast Height.

\begin{tabular}{lllll}
\hline & $\begin{array}{l}\text { AGB } \\
\left(\mathrm{t} \mathrm{ha}^{-1}\right)\end{array}$ & $\begin{array}{l}\text { Mean } \\
\text { DBH }(\mathrm{cm})\end{array}$ & $\begin{array}{l}\text { Mean (Max) } \\
\text { height }(\mathrm{m})\end{array}$ & Forest type \\
\hline Kinglake: wet forest & 500 & 40 & $20(54)$ & Eucalyptus \\
Kinglake: damp forest & 400 & 30 & $17(32)$ & Eucalyptus \\
Kinglake: forby forest & 280 & 35 & $20(32)$ & Eucalyptus \\
Iron Complex & 266 & $18-67^{*}$ & $9-33^{*}(64)$ & Mixed \\
Rooster Rock & 84 & $20-42^{*}$ & $13-27^{*}(67)$ & Coniferous \\
Columbia River Rd. & 69 & $14-34^{*}$ & $11-20^{*}(46)$ & Coniferous \\
Aliaga, Los Olmos, Teruel & 37 & 20 & $8(20)$ & Coniferous \\
\hline
\end{tabular}

* species dependent

Table 2 Landsat TM images used to compute the optical index at each fire location

\begin{tabular}{llllll}
\hline Fire & Pre-fire & Post-fire & Fire & Pre-fire & Post-fire \\
\hline $\begin{array}{l}\text { Aliaga, Los Olmos } \\
\text { Path 199 Row 032 }\end{array}$ & 2009.06 .22 & 2009.09 .26 & $\begin{array}{l}\text { Iron Complex } \\
\text { Path 045 Row 032 }\end{array}$ & 2007.07 .28 & 2009.07 .17 \\
\hline $\begin{array}{l}\text { Zuera } \\
\text { Path 199 Row 031 }\end{array}$ & 2008.07 .21 & 2008.08 .22 & $\begin{array}{l}\text { Rooster Rock } \\
\text { Path 045 Row 029 }\end{array}$ & 2010.07 .20 & 2011.07 .23 \\
\hline $\begin{array}{l}\text { Kinglake } \\
\text { Path 092 Row 086 }\end{array}$ & 2008.03 .01 & 2009.04 .21 & $\begin{array}{l}\text { Columbia River Rd } \\
\text { Path 045 Row 026 }\end{array}$ & 2008.07 .28 & 2008.08 .15 \\
\hline
\end{tabular}

Table 3 Radar datasets available for each fire location. The cumulative precipitation ( $\mathrm{mm}$ ) three days prior to acquisition is given as the average for the closest meteorological stations. In parenthesis precipitation (mm) recorded for the radar acquisition date is provided. Post-fire data sets are shown in italics. The fire date is shown in parenthesis.

\begin{tabular}{|c|c|c|c|c|c|}
\hline $\begin{array}{l}\text { Fire name, Fire date and } \\
\text { SAR acquisition mode }\end{array}$ & $\begin{array}{l}\text { Acquisition } \\
\text { date }\end{array}$ & $\begin{array}{l}\text { Cumulative } \\
\text { precipitations }\end{array}$ & $\begin{array}{l}\text { Fire name, Fire date and } \\
\text { SAR acquisition mode }\end{array}$ & $\begin{array}{l}\text { Acquisition } \\
\text { date }\end{array}$ & $\begin{array}{l}\text { Cumulative } \\
\text { precipitations }\end{array}$ \\
\hline \multirow{9}{*}{$\begin{array}{c}\text { Aliaga and Los Olmos } \\
\text { (2009.07.21-29) } \\
\text { Fine Beam Dual } \\
\text { Path } 665 \\
\text { Frame } 800\end{array}$} & 2007.06 .30 & $0.1(0.0)$ & \multirow{9}{*}{$\begin{array}{c}\text { Zuera } \\
\text { (2008.08.06-16) } \\
\text { Fine Beam Dual } \\
\text { Path } 665 \\
\text { Frame } 830\end{array}$} & 2007.06 .30 & $0.0(0.0)$ \\
\hline & 2007.08 .15 & $2.4(0.0)$ & & 2007.08 .15 & $0.7(0.0)$ \\
\hline & 2007.09 .30 & $2.9(0.0)$ & & 2007.09.30 & $1.1(0.0)$ \\
\hline & 2008.05 .17 & $21.5(1.6)$ & & 2008.05 .17 & 13.9 (1.8) \\
\hline & 2008.07 .02 & $9.2(0.0)$ & & 2008.07 .02 & $0.0(0.0)$ \\
\hline & 2009.08.20 & $0.0(0.0)$ & & 2009.08.20 & $0.0(0.0)$ \\
\hline & 2009.10 .05 & $0.0(0.0)$ & & 2009.10 .05 & $0.0(0.0)$ \\
\hline & 2010.05.23 & $0.0(0.0)$ & & 2010.05.23 & $0.0(0.0)$ \\
\hline & 2010.07.08 & $0.4(0.4)$ & & 2010.07.08 & $0.0(0.0)$ \\
\hline \multirow{6}{*}{$\begin{array}{c}\text { Iron Complex } \\
\text { (2008.06.21) } \\
\text { Fine Beam Dual } \\
\text { Path } 223 \\
\text { Frame } 800\end{array}$} & 2007.06 .14 & $0.0(0.0)$ & \multirow{6}{*}{$\begin{array}{c}\text { Rooster Rock } \\
\text { (2010.08.02) } \\
\text { Fine Beam Dual } \\
\text { Path } 218 \\
\text { Frame } 870\end{array}$} & 2007.06 .21 & $5.0(\mathrm{~N} / \mathrm{A})$ \\
\hline & 2007.09 .14 & $0.0(0.0)$ & & 2007.08 .06 & $5.0(0.0)$ \\
\hline & 2008.05.01 & $0.6(0.0)$ & & 2008.06.23 & $1.3(1.3)$ \\
\hline & 2008.06.16 & $0.0(0.0)$ & & 2009.06.26 & $1.3(1.3)$ \\
\hline & 2009.06.19 & $0.0(0.0)$ & & 2010.06.29 & $\mathrm{N} / \mathrm{A}(\mathrm{N} / \mathrm{A})$ \\
\hline & 2010.05 .07 & $0.2(0.0)$ & & 2010.09.29 & $1.3(0.0)$ \\
\hline \multirow{10}{*}{$\begin{array}{c}\text { Columbia River Road } \\
\text { (2008.08.07) } \\
\text { Fine Beam Dual } \\
\text { Path } 214 \\
\text { Frame } 950\end{array}$} & 2007.06 .11 & $0.3(0.0)$ & \multirow{10}{*}{$\begin{array}{c}\text { Kinglake } \\
\text { (2009.02.07-03.14) } \\
\text { Fine Beam Dual } \\
\text { Path } 382 \\
\text { Frame } 6420\end{array}$} & 2007.07.19 & 35.3 (9.9) \\
\hline & 2007.07.27 & $0.0(0.0)$ & & 2007.09.03 & $5.8(1.8)$ \\
\hline & 2008.07.29 & $0.0(0.0)$ & & 2007.10 .19 & $3.6(0)$ \\
\hline & 2008.09 .13 & $0.8(0.0)$ & & 2008.09.05 & 7 (1.5) \\
\hline & 2009.08.01 & $4.0(0.0)$ & & 2008.10.21 & $0.3(0.3)$ \\
\hline & 2010.08.04 & $7.3(0.6)$ & & 2009.07.24 & $16.7(1.4)$ \\
\hline & 2010.09.19 & 15.7 (9.9) & & 2009.09 .08 & $15.2(2)$ \\
\hline & 2010.11 .04 & $5.6(1.7)$ & & 2009.10.24dd & $17.1(11.6)$ \\
\hline & & & & 2010.09.11 & $0.9(0.1)$ \\
\hline & & & & 2010.10.27 & $27.8(6.1)$ \\
\hline
\end{tabular}

dd - dry date post-fire image used in the analysis 
Table 4 Indicators of fire severity retrieval accuracy from radar backscatter intensity, optical indices and joint use of radar and optical indices (R\&O) for each individual fire and pooled by forest types. $\mathrm{R}^{2}$ - model coefficient of determination, $\mathrm{r}$ - correlation between observed and predicted values, RMSE Root Mean Squared Error, BIC -Bayesian Information Criterion, RBR $_{\mathrm{HV}}$ - Radar Burn Ratio (HV polarization), and dNBR - differenced Normalized Burn Ratio.

\begin{tabular}{|c|c|c|c|c|c|c|c|c|c|c|c|c|c|c|c|c|c|c|c|}
\hline & \multicolumn{3}{|c|}{$\mathrm{R}^{2 *}$} & \multicolumn{3}{|c|}{ RMSE } & \multicolumn{3}{|c|}{$\mathrm{r}$} & \multicolumn{3}{|c|}{ bias } & \multicolumn{3}{|c|}{ Overall accuracy } & \multicolumn{3}{|c|}{$\mathrm{BIC}$} & \multirow{2}{*}{$\begin{array}{c}\text { Number } \\
\text { of samples }\end{array}$} \\
\hline & RBR & INBR & $\mathrm{R} \& \mathrm{O}$ & RBR & dNBR & $\mathrm{R} \& \mathrm{O}$ & RBR & dNBR & $\mathrm{R} \& \mathrm{O}$ & RBR & dNBR & $\mathrm{R} \& \mathrm{O}$ & RBR & $\mathrm{ANBF}$ & $\mathrm{R} \& \mathrm{O}$ & RBR & dNBR & $\mathrm{R} \& \mathrm{O}$ & \\
\hline \multicolumn{20}{|c|}{ Plot } \\
\hline Aliaga & 0.56 & 0.76 & 0.76 & 0.77 & 0.58 & 0.60 & 0.76 & 0.85 & 0.84 & 0.00 & 0.00 & 0.00 & 0.55 & 0.61 & 0.64 & 110 & 87 & 91 & 44 \\
\hline Kinglake: wet & 0.30 & 0.64 & 0.64 & 0.66 & 0.48 & 0.48 & 0.64 & 0.78 & 0.79 & 0.00 & 0.00 & 0.00 & 0.67 & 0.77 & 0.78 & 305 & 214 & 217 & 45 \\
\hline Kinglake: damp & 0.39 & 0.65 & 0.66 & 0.73 & 0.56 & 0.55 & 0.69 & 0.80 & 0.80 & 0.00 & 0.00 & 0.00 & 0.59 & 0.72 & 0.69 & 421 & 326 & 324 & 146 \\
\hline Kinglake: forby & 0.58 & 0.72 & 0.78 & 0.56 & 0.49 & 0.44 & 0.77 & 0.81 & 0.85 & 0.00 & 0.01 & 0.01 & 0.62 & 0.80 & 0.76 & 84 & 69 & 62 & 185 \\
\hline Los Olmos & 0.55 & 0.85 & 0.90 & 0.66 & 0.40 & 0.35 & 0.74 & 0.90 & 0.92 & 0.00 & 0.00 & 0.00 & 0.69 & 0.84 & 0.84 & 69 & 38 & 30 & 32 \\
\hline Rooster Rock & 0.58 & 0.82 & 0.88 & 0.69 & 0.46 & 0.41 & 0.77 & 0.89 & 0.91 & 0.00 & 0.00 & 0.01 & 0.65 & 0.79 & 0.71 & 78 & 52 & 43 & 34 \\
\hline Columbia River Rd. & 0.61 & 0.64 & 0.75 & 0.65 & 0.63 & 0.55 & 0.79 & 0.77 & 0.83 & 0.00 & 0.00 & 0.01 & 0.61 & 0.47 & 0.61 & 78 & 79 & 69 & 36 \\
\hline Zuera & 0.86 & 0.86 & 0.92 & 0.39 & 0.39 & 0.31 & 0.93 & 0.92 & 0.95 & 0.00 & 0.00 & 0.00 & 0.81 & 0.76 & 0.82 & 120 & 125 & 70 & 118 \\
\hline All coniferous & 0.60 & 0.77 & 0.80 & 0.66 & 0.50 & 0.47 & 0.80 & 0.87 & 0.89 & 0.00 & 0.00 & 0.00 & 0.66 & 0.72 & 0.72 & 125 & 121 & 103 & 264 \\
\hline All eucalyptus & 0.40 & 0.66 & 0.67 & 0.69 & 0.51 & 0.51 & 0.70 & 0.81 & 0.82 & 0.00 & 0.00 & 0.00 & 0.62 & 0.74 & 0.74 & 175 & 164 & 154 & 376 \\
\hline \multicolumn{20}{|c|}{ Overstory } \\
\hline Aliaga & 0.80 & 0.90 & 0.90 & 0.55 & 0.39 & 0.41 & 0.89 & 0.94 & 0.94 & 0.00 & 0.00 & 0.00 & 0.73 & 0.77 & 0.75 & 81 & 53 & 56 & 44 \\
\hline Iron Complex & 0.36 & 0.81 & 0.81 & 1.06 & 0.59 & 0.60 & 0.66 & 0.89 & 0.88 & 0.00 & 0.00 & -0.01 & 0.40 & 0.73 & 0.73 & 162 & 102 & 106 & 52 \\
\hline Kinglake: forby & 0.63 & 0.89 & 0.91 & 0.58 & 0.35 & 0.32 & 0.80 & 0.93 & 0.94 & 0.00 & 0.00 & 0.01 & 0.56 & 0.82 & 0.80 & 87 & 35 & 30 & 185 \\
\hline Los Olmos & 0.68 & 0.84 & 0.93 & 0.65 & 0.45 & 0.33 & 0.82 & 0.90 & 0.95 & 0.00 & 0.00 & 0.01 & 0.72 & 0.72 & 0.78 & 68 & 49 & 29 & 32 \\
\hline Rooster Rock & 0.57 & 0.60 & 0.71 & 0.81 & 0.81 & 0.71 & 0.77 & 0.74 & 0.81 & 0.00 & 0.00 & 0.01 & 0.65 & 0.76 & 0.68 & 91 & 92 & 84 & 34 \\
\hline Columbia River Rd. & 0.59 & 0.65 & 0.74 & 0.85 & 0.79 & 0.70 & 0.78 & 0.78 & 0.83 & 0.01 & 0.00 & 0.01 & 0.58 & 0.56 & 0.56 & 97 & 95 & 87 & 36 \\
\hline Zuera & 0.78 & 0.86 & 0.89 & 0.53 & 0.42 & 0.38 & 0.89 & 0.93 & 0.94 & 0.00 & 0.00 & 0.00 & 0.77 & 0.81 & 0.81 & 197 & 143 & 120 & 118 \\
\hline All conif & 0.62 & 0.77 & 0.80 & 0.72 & 0.56 & 0.53 & 0.81 & 0.88 & 0.89 & 0.00 & 0.00 & 0.00 & 0.63 & 0.71 & 0.70 & 148 & 148 & 132 & 264 \\
\hline All eucalyptus & 0.59 & 0.86 & 0.87 & 0.67 & 0.39 & 0.38 & 0.79 & 0.93 & 0.93 & 0.00 & 0.00 & 0.00 & 0.63 & 0.73 & 0.73 & 137 & 92 & 74 & 376 \\
\hline
\end{tabular}

*all models were statistically significant $(\mathrm{p}<0.05)$ 
Table 5 Confusion matrices for coniferous and eucalypt forests (pooled data). Fire severity estimated using the additive model (Eq3.) for the overstory layer.

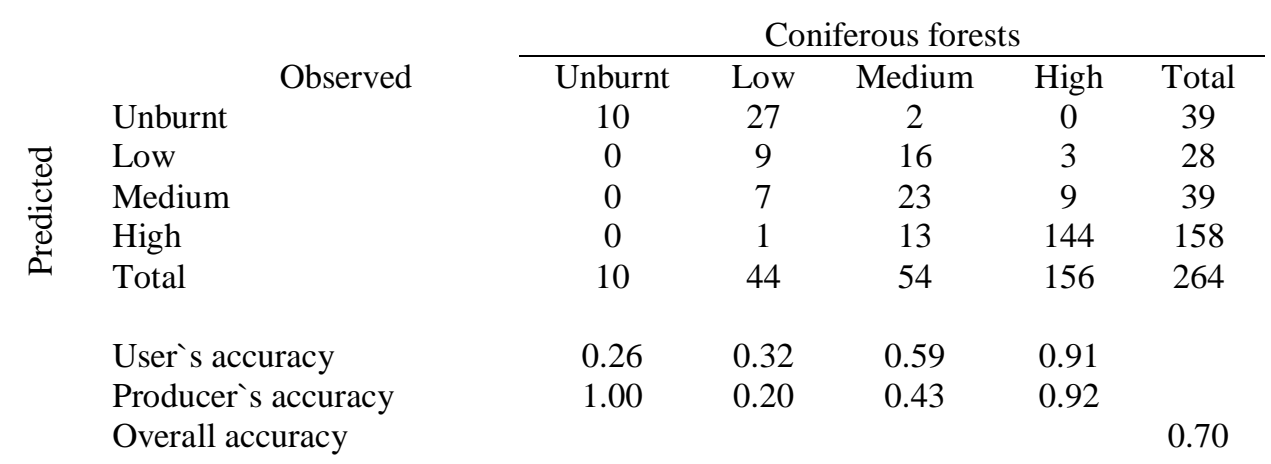

\begin{tabular}{ccccc}
\multicolumn{5}{c}{ Eucalypt forests } \\
\hline Unburnt & Low & Medium & High & Total \\
8 & 31 & 4 & 0 & 43 \\
5 & 56 & 12 & 0 & 73 \\
0 & 12 & 19 & 8 & 39 \\
0 & 0 & 28 & 193 & 221 \\
13 & 99 & 63 & 201 & 376 \\
& & & & \\
0.19 & 0.77 & 0.49 & 0.87 & \\
0.62 & 0.57 & 0.30 & 0.96 & \\
& & & & 0.73
\end{tabular}

